\title{
ARTIFICIAL INTELLIGENCE IN STOCK MARKET INVESTMENT
}

\author{
Badri Narayan Mohapatra*, ORCID ID: 0000-0003-1906-9932, \\ Bhagwat Nagargoje, Prajwal Zurunge, Suraj More \\ Savitribai Phule Pune University, AISSMS IOIT, Pune, INDIA \\ *Corresponding author: Badri Narayan Mohapatra, badri1.mohapatra@gmail.com
}

Received: 06. 28. 2021

Accepted: 08. 11. 2021

\begin{abstract}
This study investigates the selection of stock from huge stock markets and by using good selection tools so that it will give a good return value. It helps investor to find an easy decision regarding their investment in stock market individually with effective collection of trading activities. Many artificial intelligence (Al) techniques are untested in the financial crisis scenario. This research really helpful to the investor in the stock selection and stock purchase decision. $\mathrm{Al}$ is also a one of the hottest topic for most industries, researchers and investors. The financial market is easy to analyze with multiple charts, due to the application of artificial intelligence.
\end{abstract}

Keywords: stock market, artificial intelligence, trading, investment, financial.

\section{Introduction}

Stock forecasting is very important because based on this one should have to decide his/her financial decision [1]. However stock market fluctuations may change the mood of the person's investment. Rate of risk also effect the investor's mind. But stock market plays in the mobilization of capital as well as it returns interesting results like low risk in long run investment.

Even though no sure-shot formula has discovered yet but few tools with certain rules give more chances for getting good return. Proper investigation with proper decision should refine to achieve the target amount [2]. For this proper research work should require with investing different stocks. Proper knowledge and understanding are highly recommended before taking any investment in the stock and also involves regularly through the market cycle. One should also look of investing money in a very systematic approaches with a disciplined investment will give good return for a long term plan [3]. Emotions never make the judgment beginners may start with low risk and making diversification of portfolio [4 - 5]. Also each time same kind of return is not possible, so one should think realistic expectation and each time one should monitor the growth of the investment by proper use of risk tolerance with different goals and timelines [6].

\section{Strategies in stock market}

Before going to think any strategies there should be require of depth knowledge and sufficient research should require to get good return from stock market. 
Strategies like fundamental analysis, technical analysis, growth investing, qualitative analysis, buy and hold, averaging down, any one strategies may be best for the stock market [7]. One should have to know how to avoid risk and will get the benefits from stock market. Even one have small amount of money but can start investing in share market. Diversifying strategies simple means that investor money will not be in a single basket, but that money is spreading for different sectors. Daily basis technical analysis and for long term fundamental analysis are good.

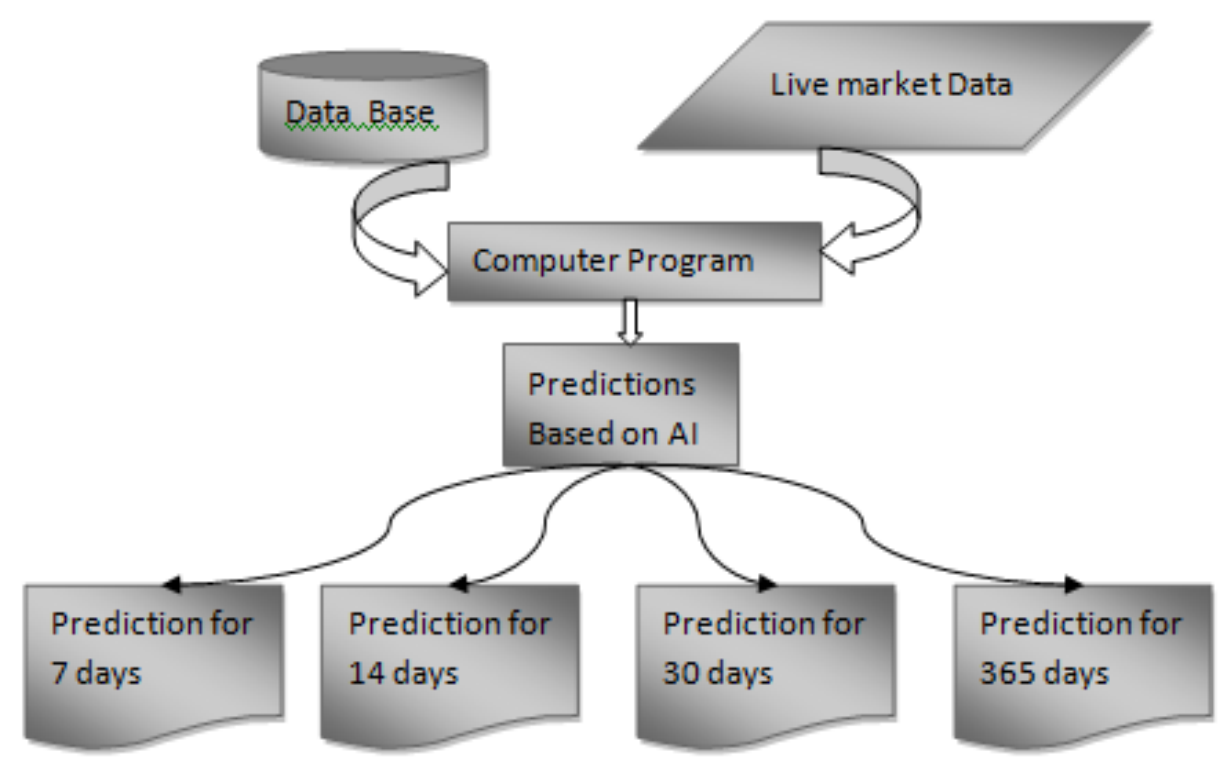

Figure 1. Prediction based on Al.

\section{Al Tools}

In today's market so many tools which will give indication of stock market like onbalance volume, accumulation, aroon indicator, RSI, MACD, Etrade, Trade station, Market gear, meta stock, stock charts and many more [8].

Simulations tool like trade station, TD Ameritrade, Invest opedia and virtual stock exchange which helps the capitalizes for analysis in the market.

Risk-Reward Ratio is a non linear approach to access the risk/reward, by divide the net profit with by the price of your highest risk [9]. Some interesting analysis can be possible through MACD, Moving average and parabolic sar [10 - 12].Machine learning also plays a important parameter [13]. Al based prediction can be visualize from figure 1.

\section{Al in stock market}

In artificial intelligence analysis it helps to provide results for each and every milliseconds. Al have started the magical role in trading. It gives information with accurate and quick by prediction of stock prices by using the previous historical data. Basically it combines the community of trading and by scanning all the trading as a result it perform better.

Even if many companies use Al to make benefit for the economies like Amazon uses Al for product recommendation to customer. Through Al Netfix make different content creation based on this artificial Intelligence and make an huge demand on the current scenarios. Companies are adopting Al for different sectors like low Al adoption for travel/ 
Tourism, education and health care system. basically retail and media, entertainment uses medium Al adoption. For automation and for finance services uses high Al adoption.

In financial for portfolio management Al techniques can help and improve the performance. Now a day's the ability of AI make it as essential for trading. Al helps in model validation, back testing, trading, portfolio composition also helps to finding the fraud detection in financial services.

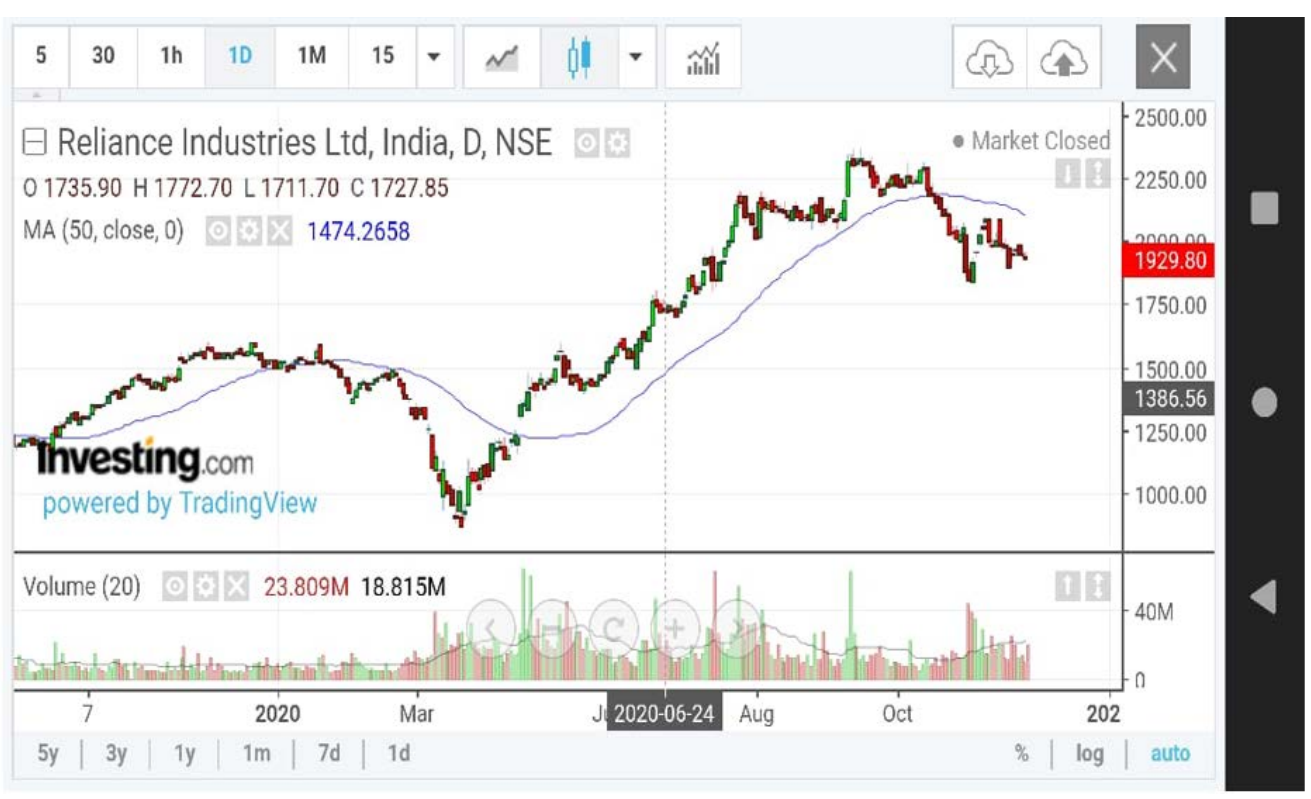

Figure 2. Moving average.

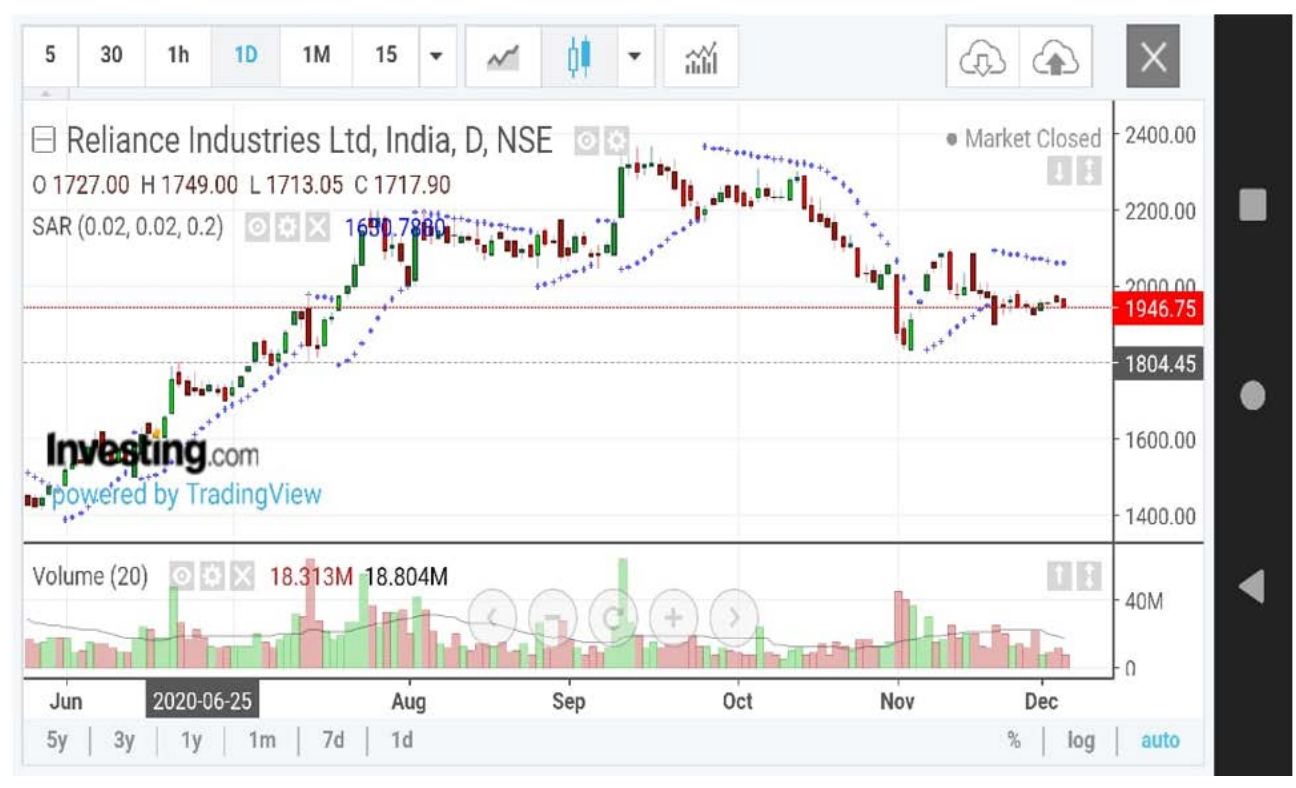

Figure 3. Parabolic Sar.

Different type moving average can be calculate by using tool, figure 2 shows for moving average strategies and figure 3 represents parabolic sar. Parabolic sar signals when close crossing buy or close crossing below sell.

Trading decision can be success especially when there will be a technical analysis. Technical analysis also help to understanding the core concept of trading. 


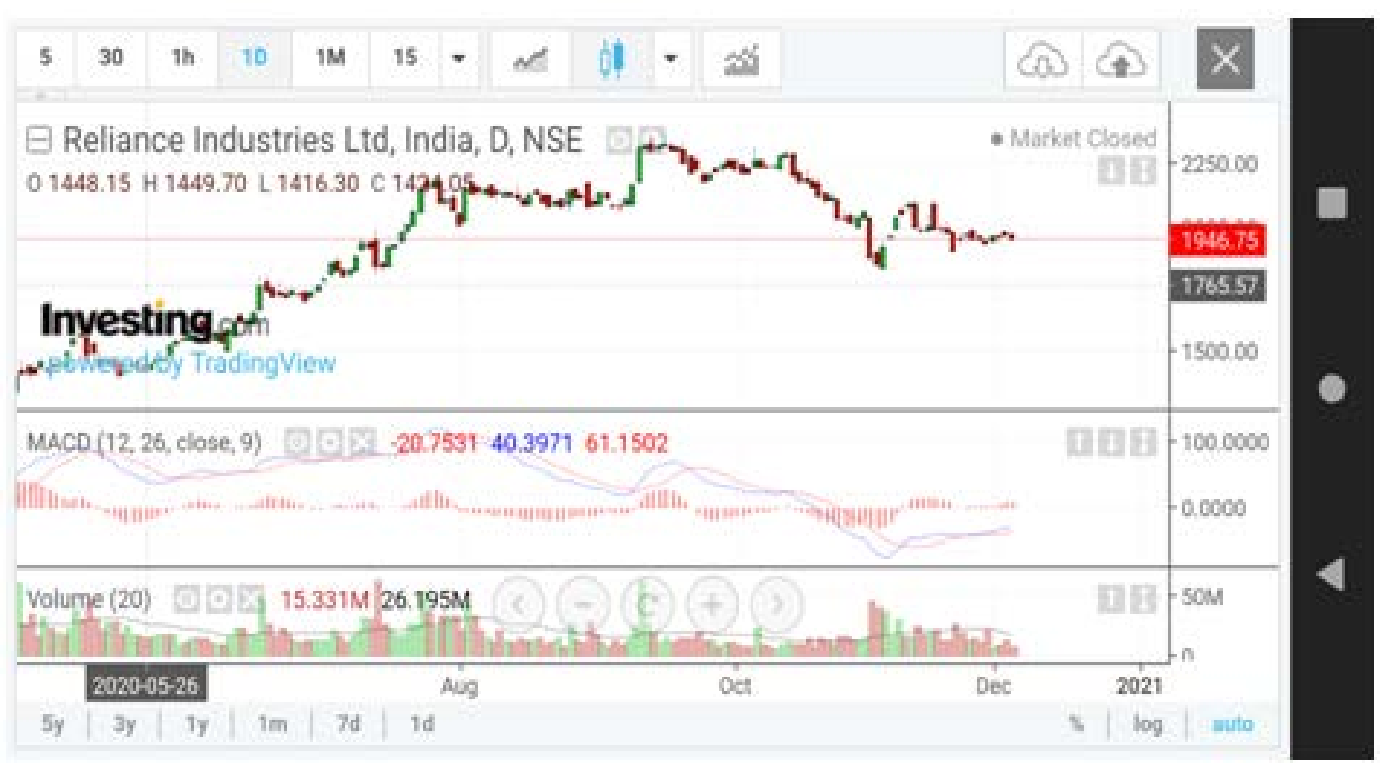

Figure 4. Moving average convergence divergence.

Profitable trading set up can be made by MACD (Moving average convergence divergence). All the figures 2, 3 and 4 represents the reliance industries Itd India NSE, so all type of analysis can be performed within few seconds through the analysis tool.

By using artificial intelligence, smart trading can be possible, which is very fast and accurate to analyze different pattern with high speed. It does not need any human intervention. Even in millisecond it gives result without require of human inputs.

Comparing between two stocks can be easily predicted. For an example considering two shares comparison of reliance and Larsen, which is shown in figure 5.

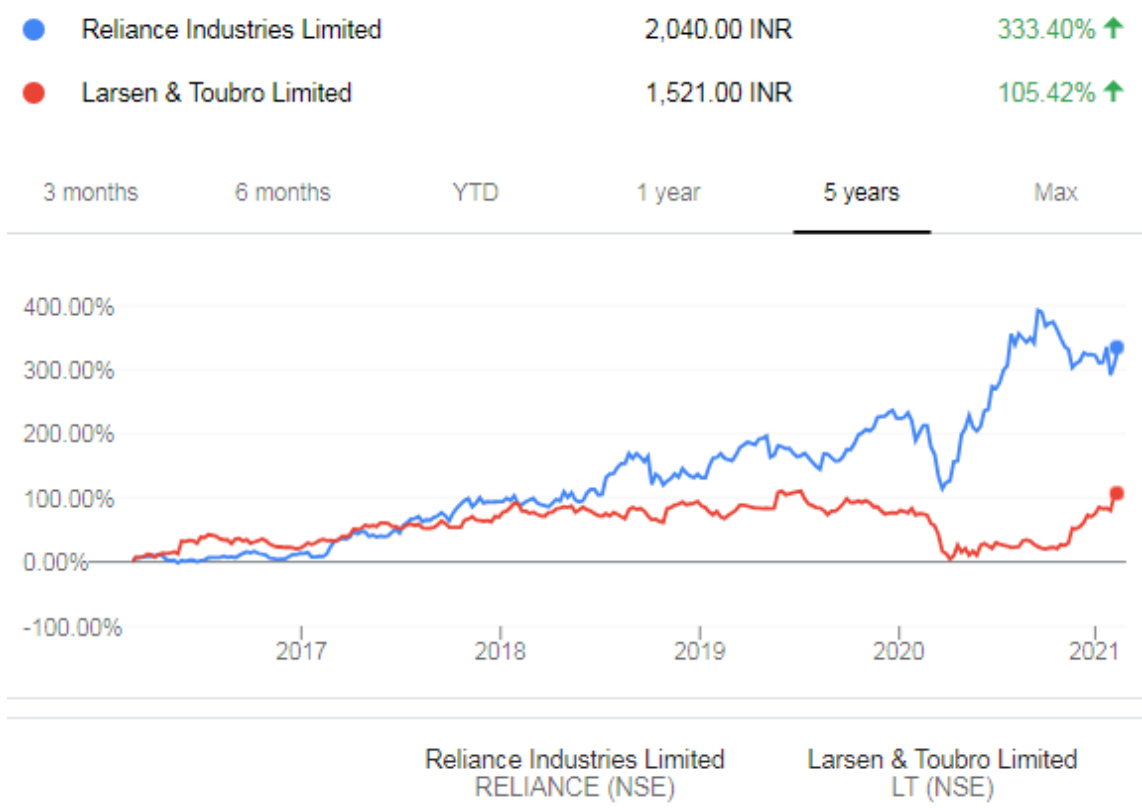

Figure 5. Easy comparison of two shares.

Now companies like Google, Microsoft and Netfix and many more uses Al to improve product design and gain strategies.

Now a days Al and ML play a key factor behind the existing stock. It is also started helping chatbot trading. Tt really helps to analyze massive data. 


\section{Conclusions}

One should get good foundation before starting any investment to the stock market. The research may be informative for the readers. Readers should take interest by proper understanding the theory of stock market and make theory into action. So one should start investing and make profits from stock market. Al actually becomes smarter and smarter. Huge analytical power can be possible when Al along with big data. Still many Al techniques are untested in financial crisis scenario. More educator trainers require to give awareness to people. Al and $\mathrm{ML}$ are moving faster which makes the regulatory framework to financial industry. It is easy to see the market situation and make require changes in portfolio management. Due to Al ,it is easy to analyze financial market with multi chart layouts.

\section{References}

1. Chen L., Qiao, Z., Wang M., Wang C., Du R., \& Stanley H. E. (2018). Which artificial intelligence algorithm better predicts the Chinese stock market?. IEEE Access, 6, 48625 - 48633.

2. Santana E. J., Mastelini S. M., \& Barbon Jr S. (2019). Stock portfolio prediction by multi-target decision support. iSys-Revista Brasileira de Sistemas de Informação, 12(1), 05 - 27.

3. Al Qudah I., \& Rabhi F. A. (2019, December). Systematic Approach to Quantify Impact of News Sentiment on Financial Markets. In 2019 International Conference on Computational Intelligence and Knowledge Economy (ICCIKE) (pp. 60-65). IEEE.

4. Baker H. K., Nofsinger J. R., \& Spieler A. C. (2020). Designing Your Portfolio: The Role of Asset Allocation, Diversification, and Rebalancing. In The Savvy Investor's Guide to Building Wealth Through Traditional Investments. Emerald Publishing Limited.

5. Yavas B. F., Grave K., \& Vardiabasis D. (2019). Diversification strategies and equity market performances. Review of International Business and Strategy.

6. Nti I. K., Adekoya A. F., \& Weyori B. A. (2019). A systematic review of fundamental and technical analysis of stock market predictions. Artificial Intelligence Review, 1 - 51.

7. Shrier, D., Canale, G., \& Pentland, A. (2016). Mobile money \& payments: Technology trends. Massachusetts Inst. Technol, 27.

8. O'Halloran S., \& Nowaczyk N. (2019). An artificial intelligence approach to regulating systemic risk. Frontiers in Artificial Intelligence, 2, 7.

9. Vaidya R. (2020). Moving Average Convergence-Divergence (MACD) Trading Rule: An Application in Nepalese Stock Market" NEPSE". Quantitative Economics and Management Studies, 1(6), 366 - 374.

10. Ostrovska K. Y. (2019). MACD technical indicator study and software implementation of decision function. System technologies, 4(123), 155 - 168.

11. Mohapatra R. K., Mohapatra B. N., \& Panda P. P. (2019). Application and security in internet of things (iots). International Journal of Technology, 9(1), 1 - 4. 